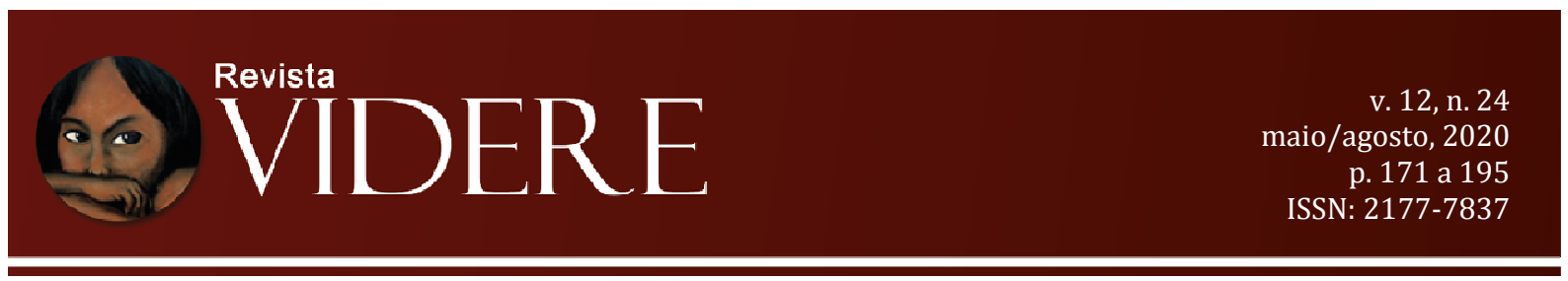

\title{
O QUE SÃO DIREITOS HUMANOS? UMA PROPOSTA DE ALTERIDADE, PLURALISMO, INTERCULTURALIDADE E DESCOLONIALIDADE
}

\author{
WHAT ARE HUMAN RIGHTS? A PROPOSAL OF OTHERNESS, LEGAL \\ PLURALISM, INTERCULTURALISM AND DECOLONIALITY
}

\author{
Guilherme Maciulevicius Mungo Brasil \\ Mestrando em Direito (UFMS), Brasil \\ Professor do Centro Universitário Anhanguera, \\ Brasil \\ E-mail: glhrmbrs1@gmail.com \\ OrcID: http://orcid.org/0000-0001-5746-1324
}

\author{
Antonio Hilario Aguilera Urquiza \\ Doutor em Antropologia (USAL), Espanha \\ Professor da Universidade Federal de Mato Grosso \\ do Sul (UFMS), Brasil \\ E-mail: hilarioaguilera@gmail.com \\ OrcID: http://orcid.org/0000-0002-3375-8630
}

RESUMO: Este estudo possui como objeto a análise da carga significativa do vocábulo "direitos humanos", buscando compreendê-lo a partir de uma abordagem jurídico-sociológica. O tema é há muito objeto de reflexões. No entanto, faltam definições que o abordem de maneira satisfatória, condizente com a realidade social, em sua materialidade histórica. Dessas constatações surge o problema de pesquisa: “o que são direitos humanos?". O objetivo não é dar resposta à pergunta, mas trazer reflexões e inquietações sobre a abordagem do que vem a ser direitos humanos. A partir do método dialético, com fim exploratório e descritivo e meio bibliográfico e documental, a pesquisa expõe inicialmente noções tradicionais de direitos humanos, marcadamente oficialistas, universalistas e deontológicas, que são contrastadas pela proposta de uma teoria crítica, com enfoque ontológico, que propõe uma definição de direitos humanos pautada na alteridade, no pluralismo jurídico, na interculturalidade e na descolonialidade.

PALAVRAS-CHAVE: Direitos de alteridade. Outridade. Direito alternativo. Direito paralelo. Giro descolonial.

ABSTRACT: This article has as its object the analysis of the actual meaning of the word "human rights", seeking to understand it from a legal-sociological approach. This subject has long been the object of reflection. However, definitions that address it satisfactorily, consistent with social reality, are lacking. From these findings the research problem arises: "what are human rights?". The goal is not to answer the question, but to bring reflections and concerns about the approach to what human rights are. From the dialectical method, with an exploratory and descriptive purpose and a bibliographical and documentary means, the research initially exposes the traditional notions of human rights, markedly officialist, universalist and deontological, which are contrasted by the proposal of a critical theory, with 
an ontological focus, which proposes a definition of human rights based on alterity, legal pluralism, interculturalism and decoloniality.

KEYWORDS: Rights of otherness. Otherness. Alternative law. Parallel law. Decolonial turn.

Todo está por hacer, cuando luchamos creamos, somo pura actividad. Todo está por inventar, por levantar, por nombrar, con su nombre más sencillo, más imprevisto, más justo, más fieramente real.

(Joaquín Herrera Flores)

\section{Introdução}

O presente estudo possui como objeto a análise da carga significativa do vocábulo "direitos humanos", buscando compreendê-lo a partir de uma abordagem jurídico-sociológica. Com efeito, a mente humana se ocupa há muito do tema, buscando compreendê-lo de acordo com determinada posição histórica, social e geográfica. No Ocidente, existem referências iniciais nos pensamentos da Grécia Antiga, passando pelos estudos religiosos do medievo e se aperfeiçoando no Iluminismo, com a concepção de uma tal dignidade, que deixará reflexos nas posteriores abordagens do tema, notadamente a partir da segunda metade do século XX. Os conceitos de direitos humanos, expressos ou não, acompanham assim determinado ideário, mostrando-se dinâmicos. Os direitos humanos do Norte global desenvolvido diferenciam-se das práticas do Sul de capitalismo periférico, da mesma forma que os direitos humanos de outrora não são os de hoje. Sequer a noção de direitos humanos concebida e positivada em 1948 se mantém perene nas primeiras décadas do século XXI. Vivemos hoje a era da PósModernidade - em que pesem as discussões a esse respeito - marcada pelo processo de globalização, em que a compressão de tempo e espaço tem alterado todos os aspectos da vida humana, como o cultural, o estético, o familiar, o econômico, o comunicacional etc. O campo epistemológico não poderia passar incólume. Nosso conhecimento é cada vez mais célere e raso. Consequentemente, a noção de direitos humanos, hoje, em geral, reúne os adjetivos próprios de um fast food: é rápida, de pouco conteúdo, subjugada à lógica capitalista e ao padrão cultural hegemônico.

Ademais das ideias superficiais que o rodeiam, o tema "direitos humanos" ainda carrega, de forma acrítica, muitas das certezas da teoria jurídica positivista de cem anos atrás. Além de pouco atual, essa abordagem não condiz (nunca o fez) com a realidade social. $\mathrm{O}$ fetiche pelo raciocínio totalizante, dogmático e deontológico reduz demasiadamente o potencial significativo e libertador dos direitos humanos. É necessário repensar, então, o que seriam direitos humanos na atualidade, de acordo com uma teoria crítica. 
O problema encontrado a partir da reflexão sobre o tema é sintetizado pela pergunta que intitula este trabalho: “o que são direitos humanos?”. Mas não se engane o leitor ou a leitora: não se apresenta como objetivo dar uma definição a fenômeno tão complexo, de modo a dar resposta à questão feita. Sobretudo porque, a partir da opção teórica adotada, os direitos humanos não poderiam ser enquadrados em determinado conceito estático e abstrato, na medida em que o direito não é, ele é, dialeticamente, "sendo". Portanto, o objetivo deste artigo é, na verdade, fazer reflexões acerca do significado do termo "direitos humanos", propondo uma análise ontológica, por meio de um olhar de alteridade, com bases no pluralismo jurídico comunitário e participativo e a partir da perspectiva intercultural, de modo a produzir epistemologias descoloniais. A inquietação é o suficiente.

A pesquisa se justifica, primeiramente, pela importância do tema, tão caro à existência humana e à defesa da dignidade a ela inerente. A perspectiva aqui trabalhada é, outrossim, atual, pautada no paradigma pós-moderno e global das relações humanas, com enfoque na realidade da América-Latina. Além disso, as possíveis descobertas a que se pode chegar com a provocação feita têm o potencial de enriquecer os atributos que se associam à ideia de direitos humanos, trazendo para o debate ângulos de visão diferentes sobre o tema, de modo a inclusive pensar mecanismos para aprimorar a proteção dos direitos humanos, concebendo uma defesa não só centrada nas positivações e mecanismos oficiais de tutela, mas também baseada em métodos que assimilam e tratam as efetivas relações de poder no seio social.

Para cumprir a tarefa a que se dispõe, o presente trabalho será desenvolvido, quanto ao fim, por intermédio de pesquisa exploratória (aproxima-se do objeto de pesquisa com perspectiva diversa da usual) e descritiva (descreve-se construções já feitas em relação à temática); em relação aos meios, configurar-se-á em bibliográfico (partirá de fontes secundárias que abordam o tema) e documental (menciona, ainda que superficialmente, o teor de tratados internacionais). O método de pesquisa empregado é o dialético, de matriz hegeliana, com a exposição de uma ideia (a teoria tradicional dos direitos humanos), sua contraposição (demonstração da insuficiência da teoria tradicional à luz da teoria crítica) e, ao fim, uma conclusão (com a proposta de leitura dos direitos humanos apresentada), isto é, em uma relação entre tese, antítese e síntese. De maneira auxiliar, especialmente no último ponto do desenvolvimento, será empregado o método dedutivo para que se chegue a conclusões específicas a partir da validade de premissas gerais.

Com efeito, no primeiro ponto de desenvolvimento, será exposta a perspectiva oficialista de direitos humanos, baseada nas positivações domésticas e internacionais, que 
partem de uma lógica deontológica e universalista, que será colocada em xeque. No segundo item, será exposta a perspectiva crítica de direitos humanos, com enfoque ontológico e fundamentado em uma proposta de alteridade, em uma concepção de direito pluralista, com uma abordagem de interculturalidade e descolonial. A conjugação desses quatro elementos compõe as diretrizes que podem orientar uma construção válida e adequada do que vem a ser direitos humanos.

\section{Direitos humanos sob a perspectiva tradicional: constituições e tratados internacionais}

Na busca para dar resposta à questão que dá título ao trabalho, foi consultada bibliografia que se propõe a conceituar o que são direitos humanos. Com efeito, André de Carvalho Ramos afirma que direitos humanos são "um conjunto de direitos considerado indispensável para uma vida humana pautada na liberdade, igualdade e dignidade. Os direitos humanos são os direitos essenciais e indispensáveis à vida Digna" (RAMOS, 2018, p. 28). Noutro momento, o autor define que direitos humanos são aqueles "estabelecidos pelo Direito Internacional em tratados e demais normas internacionais sobre a matéria" (RAMOS, 2018, p. 53), ao passo que a “expressão 'direitos fundamentais' delimitaria aqueles direitos reconhecidos e positivados pelo Direito Constitucional de um Estado específico" (RAMOS, 2018, p. 54).

Valério Mazuolli inicia determinada obra com uma afirmação: "quando se fala em 'direitos humanos', o que tecnicamente se está a dizer é que há direitos que são garantidos por normas de índole internacional" (MAZUOLLI, 2018, p. 28). Afirma, nessa linha, que direitos humanos são os "protegidos pela ordem internacional (especialmente por meio de tratados multilaterais, globais ou regionais) contra as violações e arbitrariedades que um Estado possa cometer às pessoas sujeitas à sua jurisdição” (MAZUOLLI, 2018, p. 30).

António Enrique Pérez Luño (1991, p. 48) ensina que "os direitos humanos surgem como um conjunto de faculdades e instituições que, em cada momento histórico, concretizam as exigências de dignidade, liberdade e igualdade humanas", tais exigências, para a sua concepção, "devem ser reconhecidas positivamente pelos ordenamentos jurídicos, nos planos nacional e internacional".

Esses conceitos, reproduzidos em larga escala com alguma variação entre si têm em comum o fato de, em maior ou menor medida, depositarem significativa importância na Declaração Universal dos Direitos Humanos de 1948 e nos tratados internacionais posteriores, notadamente no Pacto Internacional sobre Direitos Civis e Políticos e no Pacto Internacional 
sobre Direitos Econômicos Sociais e Culturais, ambos de 1966, como exemplifica o seguinte excerto:

[...] o sistema internacional de direitos humanos, à medida que o tempo passa, vai se tornando mais rico e complexo, como se, do big bang representado pela proclamação da Declaração Universal, em 1948, tivesse nascido uma miríade de constelações e planetas, aqui representados pelas sucessivas e complementares dimensões dos direitos humanos, em sua inexorável universalidade, interdependência e indivisibilidade, descortinadas pela edição de novos tratados, produção doutrinária e decisões jurisprudenciais (WEIS, 2014, p 17).

Na mesma linha, em sua festejada obra "A Afirmação Histórica dos Direitos Humanos" (2017), Fábio Konder Comparato realiza a análise dos direitos humanos a partir de textos que marcaram determinadas épocas, da Magna Carta inglesa, de 1215, ao Estatuto do Tribunal Penal Internacional, de 1998. É como se, a partir de tratados e convenções, se fossem "criando e estendendo progressivamente, a todos os povos da Terra, as instituições jurídicas de defesa da dignidade humana contra a violência, o aviltamento, a exploração e a miséria” (COMPARATO, 2017, p. 13).

Percebe-se, portanto, uma tendência a se resumir a noção de direitos humanos àquilo que consta em textos positivados, seja na ordem interna - com constituições e textos de hierarquia equivalente -, seja na ordem internacional - por meio de tratados. Parece que, de forma mágica, a tinta lançada no papel (ou o caractere lançado na tela) consubstancia os direitos humanos. Essa é uma perspectiva oficialista, autorreferente e de caráter deontológico. Define-se direitos humanos não pelo o que são na essência, mas pelo que está escrito em determinado diploma e pelo conjunto de normas oficiais que os regula. Herrera Flores, diante dessas definições tradicionais, questiona:

A ideia que inunda todo o discurso tradicional reside na seguinte fórmula: o conteúdo básico dos direitos é o "direito a ter direitos". Quantos direitos! E os bens que tais direitos devem garantir? $\mathrm{E}$ as condições materiais para exigi-los ou colocá-los em prática? E as lutas sociais que devem ser colocadas em prática para poder garantir um acesso mais justo a uma vida digna? (FLORES, 2009, p. 27).

A lógica oficialista pressupõe, ainda, a universalidade dos direitos humanos, fundamentados em uma racionalidade uniforme a todas as pessoas, em qualquer ponto do globo. A ideia é exposta no próprio preâmbulo da Declaração dos Direitos Humanos de 
$1948^{70}$. Esse universalismo se justifica na medida em que a declaração é produto parcial, criado por determinados países, que, no contexto da Guerra Fria que começava a se formar, pretendiam projetar sua influência e seu modo de produção neoliberal pelo planeta, em uma contemporização do expansionismo territorial que outrora marcou sua política externa.

Por isso, o caráter universal dos direitos humanos deve ser visto ao menos com cautela. Afirma-se que a visão universalista dos direitos humanos é "uma visão abstrata, vazia de conteúdo, [...] centrada na concepção ocidental de direito e do valor da identidade" (FLORES, 2002, p. 13). Outrossim, é dito que "concebidos como direitos universais, como tem sucedido, os direitos humanos tenderão sempre a ser um instrumento de 'choque de civilizações"” (SANTOS, 2004, p. 250).

Isso ocorre porque o universalismo é, na essência, etnocêntrico: parte do equivocado pressuposto de que determinada cultura, por sua superioridade, deve ser difundida $^{71}$. É a mesma lógica que se faz presente desde a Expansão Marítima, que iniciou o processo de projeção da cultura europeia pelo mundo, a pretexto de civilizar os diferentes. Esse processo, marcadamente hegemônico, é considerado o embrião da globalização.

Não por outra razão, Boaventura de Sousa Santos, ao definir globalização como o “processo pelo qual determinada condição ou entidade local estende sua influência a todo o globo e, ao fazê-lo, desenvolve a capacidade de designar como local outra condição social ou entidade rival” (2004, p. 244), inclui a própria Declaração Universal dos Direitos Humanos de 1948 como manifestação local globalmente difundida, em uma relação de poder de cimapara-baixo. Nas palavras do sociólogo português (2004, p. 251-252):

A marca ocidental, ou melhor, ocidental liberal do discurso dominante dos direitos humanos pode ser facilmente identificada [...] na Declaração Universal de 1948, elaborada sem a participação da maioria dos povos do mundo; no reconhecimento exclusivo de direitos individuais, com a única excepção do direito colectivo à autodeterminação, o qual, no entanto, foi restringido aos povos subjugados pelo colonialismo europeu; na prioridade concedida aos direitos cívicos e políticos sobre os direitos económicos, sociais e culturais; e no reconhecimento do direito de propriedade como o primeiro e, durante muitos anos, o único direito económico [sic].

\footnotetext{
70 “....] como o ideal comum a ser atingido por todos os povos e todas as nações, com o objetivo de que cada indivíduo e cada órgão da sociedade, tendo sempre em mente esta Declaração, se esforce, através do ensino e da educação, por promover o respeito a esses direitos e liberdades, e, pela adoção de medidas progressivas de caráter nacional e internacional, por assegurar o seu reconhecimento e a sua observância universal e efetiva, tanto entre os povos dos próprios Estados-Membros, quanto entre os povos dos territórios sob sua jurisdição".

71 "O etnocentrismo, de fato, é um fenômeno universal. É comum a crença de que a própria sociedade é o centro da humanidade, ou mesmo a sua única expressão. [...] É comum assim a crença no povo eleito, predestinado por seres sobrenaturais para ser superior aos demais. Tais crenças contêm o germe do racismo, da intolerância, e, frequentemente, são utilizadas para justificar a violência praticada contra os outros" (LARAIA, 2006, p. 73).
} 
A pretensão de impor valores universais a todos os povos do mundo, desconsiderando suas particularidades, é, por essas razões, contrária a uma ideia plural e inclusiva de direitos humanos, porquanto imperialista, hegemônica, etnocêntrica, violenta, monista e excludente. É esse o pano de fundo das concepções tradicionais de direitos humanos.

Na perspectiva oficialista, com fundamento universalista, há um problema não só de compreensão do fenômeno dos direitos humanos, mas também, por consequência, de efetividade. A despeito das positivações mais eloquentes no campo dos direitos humanos, remanescem situações absolutamente violadoras da dignidade do indivíduo. Esse direito posto apresenta dificuldades evidentes em se fazer concreto. Apenas a título de exemplo, conquanto o direito a igualdade esteja previsto na generalidade das constituições e tratados, a população negra continua subjugada, vítima do racismo que lhe tira oportunidades, relega a subespaços, encarcera e mata; a população LGBT+ é flagrantemente assassinada sob os olhos de todas as instituições oficiais; os pobres são lançados à margem do sistema; os povos tradicionais têm sua cultura e seu modo de ser e estar no mundo negados; a desigualdade de gêneros é inquestionável.

No âmbito internacional, os propalados sistemas regionais e mundial de proteção dos direitos humanos - o campo de justiciablidade dos direitos expressos em textos oficiais internacionais - valem-se, quando muito, de um softpower submisso ao poder geopolítico, marcadamente assimétrico. Bem demonstra essa situação a incapacidade de o Tribunal Penal Internacional levar a julgamento casos graves de violação de direitos humanos envolvendo países fora do continente africano. Em relação ao Brasil, o descumprimento da decisão da Corte Interamericana de Direitos Humanos proferida no caso Gomes Lund e outros (“Guerrilha do Araguaia”) vs. Brasil igualmente revela a insuficiência dessas soluções. Na seara não jurisdicional, é vexaminoso o fato de o Conselho de Segurança da Organização das Nações Unidades não ter tido ferramentas para impedir a invasão do Iraque pelo Estados Unidos em 2003.

Nesse contexto, a pergunta que paira é: se são os direitos humanos aqueles estabelecidos em diplomas oficiais, como pretende a teoria tradicional, por que tamanha inefetividade em sua concretização a partir dessa premissa? A justificativa comumente apresentada à falta de concretude dos direitos humanos oficiais é a do porvir: basta paciência, pois, com o tempo, o quanto positivado inserir-se-á no tecido social, mudando as relações 
entre as pessoas e efetivando esses direitos ${ }^{72}$. No entanto, o problema nos aparenta ser a insuficiência e inadequação das construções tradicionalmente feitas a respeito dos direitos humanos e seus mecanismos de defesa. Conforme descreve a historiadora Lyn Hunt (2009, p. 215-216):

As cortes e as organizações governamentais, por mais que tenham alcance internacional, serão sempre freadas por considerações geopolíticas. A história dos direitos mostra que os direitos são afinal mais bem defendidos pelos sentimentos, convicções e ações de multidões de indivíduos, que exigem respostas correspondentes ao seu senso íntimo de afronta.

À vista dessa realidade, Panikkar afirma que, na história recente, os direitos humanos oficiais são "mais um exemplo da dominação mais ou menos consciente exercida pelas nações poderosas para manter seus privilégios e defender o status quo" (PANIKKAR, 2004, p. 219). Nessa perspectiva tradicional - prossegue o pensador espanhol - "os direitos humanos continuam sendo uma arma política, conhecida há muito apenas para os nobres e cidadãos livres, ou ainda para brancos ou cristãos, ou homens etc.” (PANIKKAR, 2004, p. 219).

Marilena Chauí e Boaventura de Sousa Santos afirmam que a noção de direitos humanos usualmente utilizada foi concebida para vigorar apenas a partir do norte global, produzindo exclusões radicais, que, apesar do fim do colonialismo histórico, permanecem sob outras formas: "neocolonialismo, racismo, xenofobia, permanente estado de exceção na relação com terroristas, trabalhadores e imigrantes indocumentados, candidatos a asilo ou mesmo cidadãos comuns vítimas de políticas de austeridade ditadas pelo capital financeiro" (CHAUÍ; SANTOS, 2013, p. 44). Arrematam afirmando, quanto ao direito positivado, que “o direito internacional e as doutrinas convencionais dos direitos humanos têm sido usados como garantes dessa continuidade" (CHAUÍ; SANTOS, 2013, p. 44).

Por todas essas razões, concluímos, com Bobbio ${ }^{73}$, que as construções acerca dos direitos humanos devem ter um eixo diferente, centrando-se não em elucubrações exclusivamente abstratas, mas na preocupação "para impedir que, apesar das solenes

\footnotetext{
72 "A cristalização desses ideais em direitos efetivos, como se disse com sabedoria na disposição introdutória da Declaração [dos Direitos Humanos de 1948], far-se-á progressivamente, no plano nacional e internacional, como fruto de um esforço sistemático de educação em direitos humanos" (COMPARATO, 2017, p. 238).

73 "Com efeito, o problema que temos diante de nós não é filosófico, mas jurídico e, num sentido mais amplo, político. Não se trata de saber quais e quantos são esses direitos, qual é sua natureza e seu fundamento, se são direitos naturais ou históricos, absolutos ou relativos, mas sim qual é o modo mais seguro para garanti-los, para impedir que, apesar das solenes declarações, eles sejam continuamente violados [...]. O problema fundamental em relação aos direitos do homem, hoje, não é tanto o de justificá-los, mas o de protegê-los. Trata-se de um problema não filosófico, mas político" (BOBBIO, 2004, p. 17-23).
} 
declarações, eles sejam continuamente violados" (BOBBIO, 2004, p. 17). Assim, a concepção e consequente concretização dos direitos humanos não se cinge às positivações, mas, porque relacionadas a fenômenos humanos dinâmicos e reais, devem ter como escopo a ação política concreta.

Não se quer negar o papel dos direitos humanos positivados, seja em constituições, seja em tratados internacionais, notadamente em razão de seu papel didático, de afirmação de valores para determinados povos e de, sim, terem algum nível de justiciabilidade, nas ordens internas e internacionais. A proposta não é (de todo) anárquica. $\mathrm{O}$ ponto que se pretende ressaltar é a insuficiência dessas concepções tradicionais de direitos humanos, com impacto direto na sua efetivação, igualmente insuficiente ${ }^{74}$.

Com isso, a pretensão aqui estabelecida é a de sair do lugar-comum e das definições padrão da teoria tradicional. O que se defende é que a própria definição de direitos humanos transcende a só positivação, pois

se o Direito é reduzido à pura legalidade, já representa a dominação ilegítima, por força desta mesma suposta identidade; e este "Direito" passa, então, das normas estatais, castrado, morto e embalsamado, para o necrotério duma pseudociência, que os juristas conservadores, não à toa, chamam de "dogmática". Uma ciência verdadeira, entretanto, não pode fundar-se em "dogmas", que divinizam as normas do Estado, transformam essas práticas pseudocientíficas em tarefa de boys do imperialismo e da dominação e degradam a procura do saber numa ladainha de capangas inconscientes ou espertos (LYRA FILHO, 2006, p. 5).

Portanto, a adequada compreensão dos direitos humanos exige um olhar crítico, sensível às questões humanas subjacentes às positivações, a partir do reconhecimento de que o direito se forma, em especial, nas relações humanas reais e, por isso, nasce em um ambiente de múltiplas culturas que interagem incessantemente entre si. A teoria crítica dos direitos humanos dá o aporte para essa construção.

\section{Direitos humanos sob a perspectiva crítica: por um olhar de alteridade, pluralista, intercultural e descolonial}

Para uma compreensão ontológica dos direitos humanos - contraposta a concepções deontológicas e formalistas -, é necessário rever noções que se pretendem absolutas, abrangentes e pretas no branco, já que, em sua essência, os direitos humanos são

\footnotetext{
${ }^{74}$ Nas palavras de Joaquín Herrera Flores (2009, p.17): “Apesar da enorme importância das normas que buscam garantir a efetividade dos direitos no âmbito internacional, os direitos não podem reduzir-se às normas. Tal redução supõe, em primeiro lugar, uma falsa concepção da natureza do jurídico e, em segundo lugar, uma tautologia lógica de graves consequências sociais, econômicas, culturais e políticas".
} 
dinâmicos, têm particularidades variáveis e se revelam como uma paleta de variadas cores, em diversos matizes; são manifestações das infinitas possibilidades de fogueiras humanas, conforme sensível descrição de Galeano (2002, p. 11):

[...]. Cada pessoa brilha com luz própria entre todas as outras. Não existem duas fogueiras iguais. Existem fogueiras grandes e fogueiras pequenas e fogueiras de todas as cores. Existe gente de fogo sereno, que nem percebe o vento, e gente de fogo louco, que enche o ar de chispas. Alguns fogos, fogos bobos, não alumiam nem queimam; mas outros incendeiam a vida com tamanha vontade que é impossível olhar para eles sem pestanejar, e quem chegar perto pega fogo.

Para superar uma forma de pensar simplista, que nos levaria a raciocínios incompletos, conforme Warat, "é preciso pensar os direitos humanos desde outros lugares, menos carregados de certezas" (WARAT, 2010, p. 113), pois não existe "um legado normativo divino que se junta a uma razão universal para proclamar a positividade e a grandeza dos chamados Direitos do homem" (WARAT, 2010, p. 113).

É nesse contexto que se justifica a opção epistemológica por uma teoria crítica dos direitos humanos. Com efeito, Paulo Freire ensina que a crítica, considerada em seu aspecto amplo, compreende

aquele conhecimento que não é dogmático, nem permanente, que existe num contínuo processo de fazer-se a si próprio. E, seguindo a posição de que não existe conhecimento sem práxis, o conhecimento crítico seria aquele relacionado com um certo tipo de ação que resulta na transformação da realidade. Somente uma teoria crítica pode resultar na libertação do ser humano, pois não existe transformação da realidade sem a liberação do ser humano (FREIRE apud WOLKMER, 2002, p. 4).

Nesse sentido, a noção de crítica aplicada ao direito "debe constituirse en la afirmación de la lucha del ser humano por ver cumplimentados sus deseos y necessidades en los contextos vitales en que está situado" (FLORES, 2011, p. 15), de modo que se pode conceituar a "teoria jurídica crítica" como a "formulação teórico-prática que se revela sob a forma do exercício reflexivo capaz de questionar e romper com o que está disciplinarmente ordenado e oficialmente consagrado",75 (WOLKMER, 2002. p. 18).

\footnotetext{
${ }^{75}$ Embora seja possível identificar variações no espectro da crítica jurídica, Warat descreve elementos que funcionam como um mínimo denominador para identificação dessa teoria: “a) mostrar os mecanismos discursivos a partir dos quais a cultura jurídica converte-se em um conjunto fetichizado de discursos; b) denunciar como as funções políticas e ideológicas das concepções normativistas do Direito e do Estado encontram-se apoiadas na falaciosa separação do Direito e da Política e na utópica ideia de primazia da lei como garantia dos indivíduos; c) rever as bases epistemológicas que comandam a produção tradicional da ciência do
} 
Com essas bases, a proposta deste estudo acerca da noção crítica de direitos humanos concretiza-se por meio de um olhar sensível às questões humanas subjacentes às positivações (alteridade), com o reconhecimento de que o direito não se reduz ao quanto positivado, formando-se, em especial, nas relações humanas reais (pluralismo jurídico) e, por isso, nasce em um ambiente de múltiplas culturas que interagem incessante e freneticamente entre si (interculturalidade), possibilitando conhecimentos genuinamente locais e despidos da hegemonia colonialista (descolonial).

\subsection{Alteridade}

Ao negar o normativismo como predicado necessário à construção dos direitos humanos $^{76}$, Warat verifica que a ideia de direitos humanos tem seu núcleo na alteridade, no olhar sensível para o outro. O antropólogo francês Laplantine descreve que a descoberta da alteridade "é a de uma relação que nos permite deixar de identificar nossa pequena província de humanidade com a humanidade, e correlativamente deixar de rejeitar o presumido ‘selvagem' fora de nós mesmos” (LAPLANTINE, 2003, p. 14), de modo que, sem um olhar de alteridade, nos tornamos cegos para os outros e míopes quanto a nós mesmos.

A alteridade, ou outridade, consiste não só em ver o diferente, mas em enxergá-lo em seu contexto existencial, buscando compreendê-lo; não se trata de apenas ver o diferente como tal, mas entender o que o torna diferente e dialogar com os caracteres da diferença, acolhendo-os. Afinal, "os direitos do homem são, antes de mais nada, direitos do outro

Direito, demonstrando como as crenças teóricas dos juristas em torno da problemática da verdade e da objetividade cumprem uma função de legitimação epistêmica, através da qual pretende-se desvirtuar os conflitos sociais, apresentando-os como relações individuais harmonizáveis pelo Direito; d) superar os bizantinos debates que nos mostram o Direito a partir de uma perspectiva abstrata, forçando-nos a vê-lo como um saber eminentemente técnico, destinado à conciliação de interesses individuais, à preservação e à administração de interesses gerais [...]. Desta forma, a teoria crítica tenta recolocar o Direito no conjunto das práticas sociais que o determinam [...]; e) criar uma consciência participativa que permita aos diferentes juristas de ofício engajarem-se competentemente nos múltiplos processos decisórios, como fatores de intermediação das demandas da sociedade e não como agentes do Estado [...]; f) modificar as práticas tradicionais da pesquisa jurídica a partir de uma crítica epistemológica das teorias dominantes, de suas contradições internas e de seus efeitos ideológicos, com relação aos fenômenos que pretende organizar e explicar; g) proporcionar, nas escola de Direito, um instrumental pedagógico adequado para que os estudantes possam adquirir um modo diferente de agir, pensar e sentir, a partir de uma problemática discursiva que tente mostrar não apenas a vinculação do Direito com as relações de poder, mas também o papel das escolas de direito como produtoras de idéias e representações, que logo se entrelaçarão na atividade social como um valor a priori, pleno de certezas e dogmatismo" (WARAT, 1983, p. 39-40).

76 "la calle grita constantemente la desmesura, denunciando como son ignoradas las diferencias, reducidas a minorias excluídas [...]. Passaron siglos de normativismo y los juristas continúan teniendo devaneios de recién llegados [...]. Los juristas nunca aprendieron nada de la calle, siempre fueron prisioneros del misticismo" (WARAT, 2010, p. 128). 
homem. Dito de outro modo, são os deveres do homem para com os outros homens" (WARAT, 2004, p. 122).

Herrera Flores, ao propor um método de abordagem da teoria crítica dos direitos humanos, estabelece como parâmetro epistemológico uma "filosofia impura", em contraposição aos raciocínios que se pretendem totalizantes e "puros". O autor espanhol afirma que essa filosofia se pauta no reconhecimento das imperfeições humanas e em sua realidade, bem assim no reconhecimento de que mudanças históricas são possíveis, promovendo-se alterações na realidade, em contraponto ao suposto "fim da história" de Fukuyama. A filosofia do impuro é, ainda, "uma filosofia da alteridade, ou, o que significa o mesmo, da diferença e da pluralidade" (FLORES, 2009, p. 84).

Dessa forma, os direitos humanos devem ser considerados a partir da empatia e da sensibilidade, da capacidade de se colocar nos sapatos do outro e compreendê-lo: "a alteridade é o centro de gravidade dos Direitos humanos, seu equilíbrio vital e existencial [...]. Deveríamos começar a falar de Direito da Alteridade" (WARAT, 2010, p. 116). A alteridade é, pois, a primeira diretriz a orientar a compreensão dos direitos humanos.

\subsection{Pluralismo jurídico}

Nessa linha, a segunda baliza a ser observada é a perspectiva pluralista do direito $^{77}$, que se encarrega de superar os reducionismos positivistas e trazer à tona a complexidade das relações humanas, nelas reconhecendo fontes autênticas do direito. Wolkmer afirma que, em sua abordagem do pluralismo, o enfoque não está "no Estadonacional e no Mercado, mas [...] na força da sociedade como novo espaço comunitário de efetivação da pluralidade democrática, comprometida com a alteridade e com a diversidade cultural" (2006, p. 114). Isso porque a premissa fundamental do pluralismo é a de que o "Estado tende a deixar de ser considerado, quer como a origem única do direito, quer como a fonte da sua legitimação última” (HESPANHA, 2013, n.p.), de modo que o pluralismo jurídico comunitário-participativo "tem o mérito de revelar a rica produção legal informal

\footnotetext{
77 Este trabalho não se ocupa do pluralismo de "ordenamentos" dentro um mesmo Estado, tampouco do pluralismo internacional, em que se reconhece, no contexto da globalização, a incidência de normas supra estatais num determinado país; igualmente nos foge o pluralismo colonial, que se dedica à relação entre o direito da metrópole e o de suas colônias. A proposta de pluralismo adotada é a comunitária e participativa, com marco teórico nos trabalhos de Antonio Carlos Wolkmer e do projeto de O Direito Achado na Rua, cujo pressuposto principal é a pluralidade de fontes do Direito, com destaque das articulações internas e demandas externas de coletividades humanas organizadas em torno de determinada pauta.
} 
engendrada pelas condições materiais, lutas sociais e contradições pluriclassistas" (WOLKMER, 2006, p. 119). A base dessa vertente do pluralismo é, portanto:

a coexistência de normatividades diferenciadas que define ou não relações entre si. O pluralismo pode ter como intento práticas normativas autônomas e autênticas, geradas por diferentes forças sociais ou manifestações legais plurais e complementares, podendo ou não ser reconhecidas, incorporadas ou controladas pelo Estado (WOLKMER, 2001, p. 222).

Em termos mais claros, a concepção pluralista nega o monopólio estatal do direito, seja em razão do contexto global de esfacelamento do Estado Nação, com a perda de seu poder de regulação interna, seja porque o direito oficial estaria desprendido das reais organizações sociais, mostrando-se tão somente uma superestrutura mantenedora do estado de coisas atual e impeditiva de progresso social. Dessa constatação, entre as múltiplas fontes do direito $^{78}$, a perspectiva de pluralismo aqui adotada reconhece nas ações de agentes sociais coletivos um nascedouro legítimo do direito, criando, dessa forma, "um espaço de decisões não controladas nem determinadas pelo Estado, mas induzidas pela sociedade, [...] definindo mecanismos plurais de exercício democrático e viabilizando cenários de reconhecimento e de afirmação de Direitos Humanos" (WOLKMER, 2006, p. 117). Chega-se, dessa forma, à noção de um pluralismo jurídico que englobe a

legitimidade de novos sujeitos coletivos, a implementação de um sistema justo de satisfação das necessidades, a democratização e descentralização de um espaço público participativo, o desenvolvimento pedagógico para uma ética concreta da alteridade a consolidação de processos conducentes a uma racionalidade emancipatória (WOLKMER, 2001, p. 20-21).

A mesma linha intelectiva é seguida pela vertente de O Direito Achado na Rua, que se mostra uma forma específica de manifestação do pluralismo jurídico, possuidora de uma perspectiva própria, focada na concretização pragmática, isto é, na praxis, de um direito não-oficial. Como o próprio nome indica, a corrente tem uma preocupação que, fugindo do Direito dos códigos, ensinado nas faculdades, centra-se nas diferentes formas jurídicas efetivamente praticadas nas relações sociais, superando a aporia jus positivismo versus

\footnotetext{
${ }^{78}$ António Manuel Hespanha (2013), em uma abordagem pluralista ampla ou "pós-estadualista”, afirma que no Direito do século XXI, as pessoas tendem a procurar o Direito "autêntico" em fontes não-estatais: na organização da vida corrente; nas práticas estabelecidas ou nas inevitáveis leis dos negócios; naquilo que é considerado como correto em certo ramo de atividade; nas normas que são estabelecidas pelas organizações representativas de um setor específico do trato social; nas normas de direito supra estadual; nos consensos e acordos que as pessoas estabelecem entre si para regular relações entre elas; nas rotinas e usos comuns e assentes. O autor, a partir dessas constatações, propõe inclusive a reestruturação da Teoria do Direito.
} 
jusnaturalismo. Assim, é negado o jusnaturalismo em virtude de sua imutabilidade, rejeitando-se a ideia de que os direitos e valores de uma sociedade sejam dados pela natureza, por desígnio divino ou pela elucubração racional; da mesma forma o positivismo é rejeitado por ser "uma redução do Direito à ordem estabelecida" (LYRA FILHO, 2006, p. 26). O Direito Achado na Rua constrói um método próprio $^{79}$ e concebe o Direito da seguinte forma:

O Direito não é; ele se faz, nesse processo histórico de libertação - enquanto desvenda progressivamente os impedimentos da liberdade não lesiva aos demais. Nasce na rua, no clamor dos espoliados e oprimidos, até se consumar, vale repetir, pela mediação dos direitos humanos, na enunciação dos princípios de uma legítima organização social da liberdade (SOUSA JÚNIOR, 2015, p. 50).

Nesse sentido, a linha de O Direito Achado na Rua entende que o padrão de legitimidade das possíveis fontes do direito não está em seu grau de positivação, mas no vetor histórico e concreto, extraindo, assim "o sumo e o extrato do processo libertador a que se dá o nome de Direitos Humanos (e, note-se, não apenas as declarações, por assim dizer oficiais desses Direitos, porém os Direitos mesmos, emergentes e ainda não 'declarados')" (CARNEIRO, et al, 2015, p. 69). Logo, para que não resta dúvidas: os direitos humanos transcendem os normativismos dogmáticos.

\subsection{Interculturalidade (crítica)}

Todos esses raciocínios convergem para a abordagem intercultural dos direitos humanos, contrapondo a lógica hegemônica do universalismo e abrindo o hermético relativismo. Há, assim, uma relação intensa entre alteridade, pluralismo e interculturalidade, o terceiro ponto da proposta aqui feita:

Nessa perspectiva, o pluralismo comprometido com a alteridade e com a diversidade cultural projeta-se como instrumento contra hegemônico, porquanto mobiliza concretamente a relação mais direta entre novos sujeitos

\footnotetext{
79 “'O sentido que orienta o trabalho político e teórico de O Direito Achado na Rua consiste em compreender e refletir sobre a atuação jurídica dos novos sujeitos sociais e, com base na análise das experiências populares de criação do direito: 1. Determinar o espaço político no qual se desenvolvem as práticas sociais que enunciam direitos, a partir mesmo de sua constituição extralegal, por exemplo, direitos humanos; 2. Definir a natureza jurídica do sujeito coletivo capaz de elaborar um projeto político de transformação social e elaborar a sua representação teórica como sujeito coletivo de direito; 3. Enquadrar os dados derivados destas práticas sociais criadoras de direitos e estabelecer novas categorias jurídicas para estruturar as relações solidárias de uma sociedade alternativa em que sejam superadas as condições de espoliação e de opressão do homem pelo homem e na qual o direito possa realizar-se como um projeto de legítima organização social da liberdade" (SOUSA JÚNIOR, 1993, p. 10).
} 
sociais e poder institucional, favorecendo a radicalização de um processo comunitário participativo, definindo mecanismos plurais de exercício democrático e viabilizando cenários de reconhecimento e de afirmação de Direitos Humanos (WOLKMER, 2006, p. 117).

A cultura, descreve Laraia, é "como uma lente através da qual o homem vê o mundo. Homens de culturas diferentes usam lentes diversas e, portanto, têm visões desencontradas das coisas" (LARAIA, 2006, p. 67). O problema, contudo, é esse desencontro das coisas, que se dá pela tendência de todos a enxergar a sua própria cultura como a mais correta e natural, levando a atitudes etnocêntricas responsáveis pela ocorrência de numerosos conflitos sociais. O modelo etnocêntrico conduz, de um lado, a posturas hegemônicas, em que se pretende impor ao diferente o seu modo de ser e estar no mundo e, de outro, a posturas de introversão cultural e de negativa de interação com o diferente. São essas, respectivamente, em linhas muito gerais, as visões universalista e relativista dos direitos humanos. É necessário superá-las. Nas palavras de Boaventura de Souza Santos:

Contra o universalismo, há que propor diálogos interculturais sobre preocupações isomórficas, isto é, sobre preocupações convergentes ainda que expressa em linguagens distintas e a partir de universos culturais diferentes. Contra o relativismo, há que desenvolver critérios que permitam distinguir uma política progressista de uma política conservadora de direitos humanos, uma política de capacitação de uma política de desarme, uma política emancipatória de uma política regulatória (SANTOS, 2004, p. 253).

O sociólogo propõe, assim, a "hermenêutica diatópica" como instrumento de diálogo entre os diferentes, em um ponto de equilíbrio entre o universalismo e o relativismo. Hermenêutica, semanticamente, é a atividade de interpretar e de dar significado. A etimologia do termo "diatópica" auxilia em sua compreensão: o prefixo grego "dia" faz referência a movimento, o radical "topos" remete a lugar. Assim, entende-se como hermenêutica diatópica a atividade interpretativa com movimento em lugares diferentes, ou, nas próprias palavras do autor, "um diálogo que se desenrola, por assim dizer, com um pé numa cultura e outro, noutra" (SANTOS, 2004, p. 257).

O que se busca é um diálogo intercultural sobre a dignidade humana que pode levar a uma concepção que se organiza como uma teia em que se relacionam vários sentidos locais, mutuamente inteligíveis. É essa a proposta de uma concepção "mestiça de direitos humanos", uma proposta que "pressupõe a aceitação do seguinte imperativo transcultural: temos o direito a ser iguais quando a diferença nos inferioriza; temos o direito a ser diferentes quando a igualdade nos descaracteriza" (SANTOS, 2004, p. 272). 
Herrera Flores segue a mesma forma de pensar ao constatar a inadequação das visões universalistas (abstrata, formal e de racionalidade jurídica) e relativistas (localista, cultural e de racionalidade material) dos direitos humanos e, a partir disso, constrói uma proposta de universalismo de chegada ou de confluência. O autor propõe, dessa forma, um diálogo intercultural que leve, ao fim e ao cabo, a pontos comuns entre os diferentes em interação, conduzindo a

um universalismo de contrastes, de entrecruzamento, de mesclas. Um universalismo impuro que propõe a inter-relação e não a superposição. Um universalismo que não aceita a visão microscópica que parte de nós mesmos, no universalismo de partida ou de retas paralelas. Trata-se de um universalismo que nos sirva de impulso para abandonar todo tipo de visão fechada, seja cultural ou epistêmica, a favor de energias nômades, migratórias, móbiles, que permitam deslocarmo-nos pelos diferentes pontos de vista sem a pretensão de negar-lhes, nem de negar-nos, a possibilidade de luta pela dignidade humana (FLORES, 2002, p. 23).

Deve-se fazer um alerta, contudo. Conforme descreve Catherine Walsh, o discurso intercultural tem sido apropriado pela lógica neoliberal, por meio de uma "interculturalidade funcional", que incorpora os grupos diferentes com a finalidade de neutralizar seu potencial libertador. Dessa forma, em vez de criar sociedades mais equitativas, esse movimento possibilita o "controle do conflito étnico e a conservação da estabilidade social, com o fim de impulsionar os imperativos econômicos do modelo neoliberal de acumulação capitalista, agora 'incluindo' os grupos historicamente excluídos” (WALSH, 2009, p. 16). Para a pensadora, são indicativas desse processo as reformas educativas e constitucionais dos anos 1990 na América Latina, que reconheceram o caráter multiétnico dos países e, com isso, introduziram políticas específicas para os indígenas e afrodescendentes, ao mesmo tempo em que esses grupos começaram a ser destinatários específicos de políticas de crédito de instituições financeiras multilaterais, como o Banco Mundial, o Bando Internacional do Desenvolvimento - BID e o Fundo Monetário Internacional - FMI. À medida que essas instituições se relacionam com grupos insurgentes e à margem do mainstream mundial, vão minando a capacidade desses grupos de gerar mudanças radicais ou substanciais nas estruturas hegemônicas ${ }^{80}$, exatamente porque introjetam neles os imperativos de acumulação capitalista. Em síntese:

80 “Ao que parece, não é mera coincidência que, ao mesmo tempo em que os movimentos indígenas estavam despertando em vários países latino-americanos, uma nova força nacional e regional de sério questionamento das estruturas e instituições do Estado, os bancos multilaterais de desenvolvimento começaram a se interessar pelo 
É uma estratégia política funcional ao sistema/mundo moderno e ainda colonial; pretende "incluir" os anteriormente excluídos dentro de um modelo globalizado de sociedade, regido não pelas pessoas, mas pelos interesses do mercado. Tal estratégia e política não buscam transformar as estruturas sociais racializadas; pelo contrário, seu objetivo é administrar a diversidade diante do que está visto como o perigo da radicalização de imaginários e agenciamento étnicos. Ao posicionar a razão neoliberal - moderna, ocidental e (re)colonial - como racionalidade única, faz pensar que seu projeto e interesse apontam para o conjunto da sociedade e a um viver melhor. Por isso, permanece sem maior questionamento (WALSH, 2009, p. 20).

A contraposição à usurpação do discurso intercultural se perfaz em uma interculturalidade crítica, cujas raízes se assentam não no Estado, nem na academia, mas nas discussões políticas postas em cena pelos movimentos sociais em seu papel de visibilizar, enfrentar e transformar as estruturas e instituições posicionam grupos, práticas e pensamentos de maneira hierarquizada:

[...] a interculturalidade crítica - como prática política - desenha outro caminho muito distinto do que traça a interculturalidade funcional. Mas tal caminho não se limita às esferas políticas, sociais e culturais; também se cruza com as do saber e do ser. Ou seja, se preocupa também com a exclusão, negação e subalternização ontológica e epistêmico-cognitiva dos grupos e sujeitos racializados; com as práticas - de desumanização e de subordinação de conhecimentos - que privilegiam alguns sobre outros, "naturalizando" a diferença e ocultando as desigualdades que se estruturam e se mantêm em seu interior. Mas, e adicionalmente, se preocupa com os seres de resistência, insurgência e oposição, os que persistem, apesar da desumanização e subordinação (WALSH, 2009, p. 23).

Por essa razão, não basta a interculturalidade como discurso vazio a apropriado por dinâmicas hegemônicas, mas é necessário ter como diretriz o reconhecimento da interculturalidade real, construída pelos próprios grupos envolvidos e com a plenitude de seu potencial transformador, isto é, a interculturalidade crítica.

\subsection{Descolonialidade}

A leitura de direitos humanos proposta, observados os parâmetros já indicados, ainda apresenta o potencial descolonial das noções a serem construídas. A alteridade, o pluralismo e a interculturalidade conduzem a uma maneira de pensar os direitos humanos 
própria da realidade social, histórica e cultural do local em que são pensados, fugindo de padrões epistêmicos colonialistas.

A realidade da América-Latina - assim como a das demais regiões colonizadas do globo - bem evidencia que, por força do processo de colonialidade ${ }^{81}$ - diferente do conceito clássico de colonialismo $^{82}$-, as maneiras de ser, produzir e pensar de povos colonizados adota como parâmetro mesmo aquele dos colonizadores, lançando à margem toda manifestação humana diversa ${ }^{83}$. É na prática da colonialidade que surgem os "ninguéns":

[...] Os ninguéns: os filhos de ninguém, os donos de nada.

Os ninguéns: os nenhuns, correndo soltos, morrendo a vida, fodidos e mal pagos:

Que não são embora sejam.

Que não falam idiomas, falam dialetos.

Que não praticam religiões, praticam superstições.

Que não fazem arte, fazem artesanato.

Que não são seres humanos, são recursos humanos.

Que não têm cultura, têm folclore.

Que não têm cara, têm braços.

Que não têm nome, têm número.

Que não aparecem na história universal, aparecem nas páginas policiais da imprensa local.

Os ninguéns, que custam menos do que a bala que os mata.

${ }^{81} \mathrm{O}$ termo diz respeito a um fenômeno histórico complexo que se estende até os dias de hoje, entendido como um padrão de poder que opera pela naturalização de hierarquias territoriais, raciais, culturais e epistêmicas. Essas hierarquias, fortemente enraizadas, possibilitam a reprodução de relações de dominação, propiciando a exploração pelo capital dos seres humanos em escala global e a subalternização dos conhecimentos, das experiências e das formas de vida (QUIJANO, 2010. p. 120).

${ }^{82} \mathrm{Na}$ definição de Quijano, trata-se do padrão de dominação e exploração em que o controle da autoridade política, dos recursos de produção e do trabalho de populações determinadas possui uma diferente identidade de suas sedes centrais (QUIJANO, 2010, p. 118).

83 "Às Américas chegou o homem heterossexual/branco/patriarcal/cristão/militar/capitalista/europeu, com as suas várias hierarquias globais enredadas e coexistentes no espaço e no tempo, as quais, por motivos de clareza da presente exposição, passarei em seguida a enumerar como se fossem independentes umas das outras: 1) Uma específica formação de classes de âmbito global, em que diversas formas de trabalho (escravatura-semi-servidão feudal, trabalho assalariado, pequena produção de mercadoria) irão coexistir e ser organizadas pelo capital enquanto fonte de produção de mais-valia através da venda de mercadorias no mercado mundial com vista ao lucro; 2) Uma divisão internacional do trabalho em centro e periferia, em que o capital organizava o trabalho na periferia de acordo com formas autoritárias e coercitivas [...]; 3) Um sistema interestatal de organizações político-militares controladas por homens europeus e institucionalizadas em administrações coloniais [...]; 4) Uma hierarquia étnico-racial global que privilegia os povos europeus relativamente aos não-europeus [...]; 5) Uma hierarquia global que privilegia os homens relativamente às mulheres e ao patriarcado europeu relativamente a outros tipos de relação entre os sexos; 6) uma hierarquia sexual que privilegia os heterossexuais relativamente aos homossexuais e lésbicas (e é importante recordar que a maioria dos povos indígenas da Américas não via a sexualidade entre homens como um comportamento patológico nem tinha qualquer ideologia homofóbica); 7) Uma hierarquia espiritual que privilegia os cristãos relativamente às espiritualidades nãocristãs/não-europeias institucionalizadas na globalização da igreja cristã (católica e, posteriormente, protestante); 8) Uma hierarquia epistémica que privilegia a cosmologia e o conhecimento ocidentais relativamente aos conhecimentos e às cosmologias não-ocidentais, e institucionalizada no sistema universitário global [...]; 9) Uma hierarquia linguística entre as línguas europeias e não-europeias que privilegia a comunicação e a produção de conhecimento e de teoria por parte das primeiras, e que subalterniza as últimas exclusivamente como produtoras de folclore ou cultura, mas não de conhecimento/teoria [...]" (GROSFOGUEL, 2010, p. 463-464). 
(GALEANO, 2002, p. 42)

Essa manifestação de poder fez (e faz) com que transplantássemos para o nosso seio social conhecimentos externos e descolados de nossa realidade, ignorando nossas próprias epistemologias locais, de modo a operar um "epistemicídio, ou seja, a supressão dos conhecimentos locais perpetrada por um conhecimento alienígena” (SANTOS, 2010, p. 16). Essa lógica, evidentemente, aplica-se às ideias de direitos humanos que, em geral, são observadas entre nós, justificando sua internalização de maneira acrítica. Os conceitos tradicionais, antes referidos, manifestam uma maneira colonial e hegemônica - a partir da lógica universalista - de pensar os direitos humanos. Sua inadequação já foi aqui demonstrada.

A contraposição a tais formas de dominação se deu, em um primeiro momento, por meio do pensamento pós-colonial ${ }^{84}$, cuja essência é a construção de ideias comprometidas com a superação das relações de colonização a partir da teoria crítica europeia (BALLESTRIN, 2013, p. 90-91). Em uma segunda etapa, o deslocamento dessas ideias para o Sul global, com seu consequente amadurecimento, leva ao denominado giro descolonial (ou decolonial ${ }^{85}$ ), que se constitui em um movimento de resistência teórico e prático, político e epistemológico, que edifica o paradigma descolonial a partir de visões, pensamentos e subjetividades marginais.

\footnotetext{
84 'Depreendem-se do termo 'pós-colonialismo' basicamente dois entendimentos. O primeiro diz respeito ao tempo histórico posterior aos processos de descolonização do chamado 'terceiro mundo', a partir da metade do século XX. Temporalmente, tal ideia refere-se, portanto, à independência, libertação e emancipação das sociedades exploradas pelo imperialismo e neocolonialismo - especialmente nos continentes asiático e africano. A outra utilização do termo se refere a um conjunto de contribuições teóricas oriundas principalmente dos estudos literários e culturais, que a partir dos anos 1980 ganharam evidência em algumas universidades dos Estados Unidos e da Inglaterra [...]. Mesmo que não linear, disciplinado e articulado, o argumento pós-colonial em toda sua amplitude histórica, temporal, geográfica e disciplinar percebeu a diferença colonial e intercedeu pelo colonizado" (BALLESTRIN, 2013, p. 90-91).

${ }^{85}$ Notam-se as duas diferentes grafias para designação dessas ideias. Isso porque os estudos iniciais a respeito do tema foram escritos em inglês, com emprego do termo "decoloniality", sendo incorporado nos textos brasileiros com tradução para "decolonialidade", por meio de um anglicismo. Catherine Walsh e Walter Mignolo justificam que o termo "decoloniality" (que deu origem a decolonial, sem o "s") tem semântica própria, pois se contrapõe especificamente à colonialidade, nos moldes descritos por Quijano, e não se confunde com descolonização (decolonization), em seu sentido clássico, ligado ao fim das práticas colonialistas dos séculos passados: "The point is that decoloniality has changed the terrain from aiming at forming sovereign nation-states (decolonization) out of the ruins of the colonies to aiming at decolonial horizons of liberation (decoloniality) beyond state designs, and corporate and financial desires" (MIGNOLO; WALSH, 2018, p. 125, passim). Por outro lado, minoritariamente, existe grupo que rejeita o emprego de "decolonial", preferindo "descolonial" (com "s"), abrasileirando o termo, pois a importação da palavra em inglês representa justamente a prática de assimilação do conhecimento hegemônico contra a qual se volta a linha teórica. Portanto, a utilização de "decolonial" representa uma contradição. Não que mereça censura a utilização de termos ou ideias estrangeiras que se somem à maré contra a colonialidade, mas se afigura de bom tom que ao menos o nome que indica o conjunto de ideias tenhas raízes locais. Por isso, e por não compreender que o termo "descolonial" implique em indeterminação ou confusão semântica, este estudo o adota, alinhando-se, entre outros, a Wolkmer.
} 
Nessa linha, a proposta adotada é de uma maneira de pensar os direitos humanos que rompa com o padrão colonial, concebendo-os desde a realidade latino-americana, afinando-se com o que Boaventura de Sousa Santos denomina "epistemologias do sul" ${ }^{\prime 6}$. Essa diretriz possibilita saberes afetos à nossa rica complexidade, marcada por uma miríade de línguas, culturas e cosmologias, por peculiaridades geográficas, pelo passado comum de excolônias, pela exploração experimentada, dos expedientes coloniais até os sofisticados mecanismos do capitalismo financeiro e do neoliberalismo contemporâneos. Forma-se, assim, uma epistemologia pautada em um raciocínio contra hegemônico, isto é, uma epistemologia desconolial, que permite enxergar os velhos problemas latino-americanos com novas lentes.

Essa abordagem, ressalva-se, não se direciona exclusivamente aos colonizados, aos subjugados pela colonialidade, aos "ninguéns", como maneira de enfrentamento a tudo o que não diz respeito ao seu modo próprio de ser e estar no mundo, como se justificasse um radical relativismo cultural, mas se projeta a todos aqueles, no Sul e no Norte global geográfico, dedicados à tarefa, necessariamente intercultural, de levar a efeito um pensamento marginal das relações humanas, de maneira a descontruir estruturas coloniais hegemônicas.

\subsection{Direitos humanos são...}

Neste ponto do trabalho, fixadas as premissas necessárias, é possível avançar, descrevendo-se algumas noções de direitos humanos que convergem com a abordagem aqui feita. Wolkmer afirma que, repensados a partir da teoria crítica, os direitos humanos são "uma ferramenta autêntica para uma práxis histórica de libertação. Uma práxis que é histórica, mas sem deixar de ser sócio-política enquanto expressão do "outro", do sujeito vivo, subalterno e necessitado (WOLKMER, 2016, p. 682).

Boaventura de Sousa Santos concebe direitos humanos "como a energia e a linguagem de esferas públicas, locais, nacionais e transnacional actuando em rede para garantir novas e mais intensas formas de inclusão social [sic]" (SANTOS, 2004, p. 243) e, para dar completude à noção, define

\footnotetext{
86 "Designamos a diversidade epistemológica do mundo por epistemologias do Sul. O Sul é aqui concebido metaforicamente como um campo de desafios epistêmicos, que procuram reparar os danos e impactos historicamente causados pelo capitalismo na sua relação colonial com o mundo. [...] A ideia central é [...] que o colonialismo, para além de todas as dominações por que é conhecido, foi também uma dominação epistemológica, uma relação extremamente desigual de saber-poder que conduziu à supressão de muitas formas de saber próprias dos povos e/ou nações colonizados. As epistemologias do Sul são o conjunto de intervenções epistemológicas que denunciam essa supressão, valorizam os saberes que resistiram com êxito e investigam as condições de um diálogo horizontal entre conhecimentos" (SANTOS, 2010, p. 19).
} 
a esfera pública como um campo de interação e de deliberação em que indivíduos, grupos e associações, através de retórica dialógica e regras procedimentais partilhadas, (1) estabelecem equivalências e hierarquias entre interesses, reivindicações e identidades; (2) aceitam que tais regras sejam contestadas ao longo do tempo, pelos mesmos indivíduos, grupos ou associações ou por outros, em nome de interesses, reivindicações e identidades que foram anteriormente excluídos, silenciados e desacreditados (SANTOS, 2004, p. 243).

Joaquín Herrera Flores parte do pressuposto de que "os direitos humanos são criados e recriados na medida em que vamos atuando no processo de construção social da realidade" (2009, p. 73), de modo que, para além dos oficialismos abstratos, constata o autor que "entre os direitos humanos e as políticas concretas há uma estreita relação de interdependência" (2009, p. 76). Com base nessas premissas teóricas, Joaquín Herrera Flores propõe:

Contra essas abstrações (que têm, obviamente, objetivos de justificação da ordem de dominação existente), nós pretendemos construir uma teoria que, abandonando as purezas e as idealizações (de um único sistema de relações sociais e uma única forma de entender os direitos), aposte numa concepção materialista da realidade. Em outras palavras, desejamos uma teoria que fixe uma forma de conceber o nosso mundo como um mundo real, repletos de situações de desigualdades, de diferenças e disparidades, de impurezas e mestiçagens que nunca devemos ocultar $(2009$, p. 80).

Conclui o pensador espanhol que, quando falamos em direitos humanos, "nos referimos ao resultado histórico do conjunto de processos antagonistas ao capital que abrem ou consolidam espaços de luta pela dignidade humana” (2009, p. 110).

Esses raciocínios auxiliam na compreensão da complexidade e dinamicidade dos direitos humanos, características que, à luz de todas as considerações aqui feitas, levam ao desafio de uma práxis dialética, fundada em lutas e em sociabilidades emergentes, tornando a compreensão de direitos humanos um permanente processo de construção, por meio da alteridade, do pluralismo jurídico, da interculturalidade e da descolonialidade.

Com efeito, pode-se concluir que a perspectiva crítica nos faria pensar, ao falar em direitos humanos, não só em declarações, mas em uma luta diária, real, de carne, osso e cultura, no sangue derramado e no suor dedicado, exemplificativamente, pelos coletivos organizados em torno das questões indígenas, no respeito à sua cultura e à luta pela demarcação de terras; da população negra, das comunidades quilombolas com suas especificidades à generalidade das pessoas que sofrem com o racismo estrutural tão 
impregnado em nossa dinâmica social; das reivindicações pelas pautas das bandeiras LGBT+, empenhadas no reconhecimento da diversidade de gêneros e de orientação sexual e, em última análise, na só prevalência do direito de amar e ser amado; da opressão sofrida pelos trabalhadores, que, indo além da mais-valia descrita por Marx ao tempo da Revolução Industrial, hoje tem contornos complexos, dinâmicos e fluidos na era pós-moderna da globalização; das ações concretas em prol de um meio ambiente saudável, buscando a promoção de um desenvolvimento global sustentável; da questão agrária, contra o fim da má distribuição de terras no campo; da moradia digna, buscando que todas as pessoas tenham condições de se estabelecer dignamente, evitando-se a condição da população em situação de rua; da desigualdade de gêneros, fundada, basilarmente, na premissa de que determinados papéis devem ser desempenhados por determinado gênero, colocando o feminino em patamar inferior; enfim, de todas as organizações humanas coletivas, que se voltam contra a opressão e à desigualdade em uma articulação criadora de um direito extraoficial, cuja luta só poder ser adequadamente enxergada com um olhar de alteridade, sensível ao outro e que pressupõe, para sua efetivação, o diálogo intercultural de diferentes no campo descolonial latinoamericano.

\section{Conclusão}

No presente artigo, a partir do problema pautado em se encontrar uma definição adequada para "direitos humanos", foram inicialmente abordadas noções tradicionais sobre o tema: oficiais, universalistas e deontológicas. Tradicionalmente, os direitos humanos são definidos como aqueles direitos previstos em tratados internacionais e que, quando possuem replicação em texto constitucional interno, são batizados de direitos fundamentais. Apenas isso. Para essa perspectiva, a forma tem prevalência sobre o conteúdo. Essa maneira de pensar o que são direitos humanos limita-os e os resume a positivações abstratas e descoladas da realidade, esvaziando sua potencialidade libertadora. A partir das críticas feitas a tal concepção, conclui-se por sua insuficiência e pela consequente impossibilidade de solucionar o problema proposto.

Por outro lado, como possibilidade válida à construção de um conceito de direitos humanos, assoma-se uma teoria crítica, que conduz à contraposição dos predicados oficiais, universalistas e deontológicas por diretrizes extralegais, interculturais e ontológicas, dialeticamente construídas no meio social.

Nessa linha, definir na essência o que são direitos humanos exige, em conformidade com a proposta aqui lançada, uma forma de pensar que se valha da alteridade, 
sensibilizando e permitindo uma visão ampla e acolhedora do outro; que transcenda os normativismos oficialistas, negando-se o monopólio do direito pelo Estado, em uma concepção pluralista do direito que reconheça nas organizações humanas coletivas a capacidade de criação de um direito real; que se paute do diálogo entre culturas, permitindo, em um ambiente de trocas recíprocas, a obtenção do ponto de equilíbrio entre universalismo e relativismo; que reconheça o valor dos conhecimentos locais, rompendo com a lógica da colonialidade, em um processo de descolonização epistemológica.

Essa análise, inclusive, põe em relevo o necessário caráter transdisciplinar dos direitos humanos, que, a toda evidência, não são monopolizados pelo Direito. Antes, a abordagem crítica exige, para sua intelecção, as lentes e os métodos de outras ciências humanas. É da convergência e da complementação recíproca dos pontos de vista que se validam as contribuições para a formação da noção a que se chega.

Não se nega, com a perspectiva aqui proposta, os direitos humanos positivados, interna ou internacionalmente. Antes, busca-se harmonizá-los com uma proposta crítica, refutando-se disposições abstratas sem qualquer paralelo com a realidade das relações sociais e acolhendo-se eventuais convergências entre elas e as propostas lançadas neste estudo. Outrossim, a ideia de se repensar os direitos humanos visa a trazer questionamentos sobre a forma de efetivação e tutela desses direitos, buscando uma proteção abrangente e em múltiplos fronts, seja os mecanismos tradicionais - domésticos, regionais e mundial -, seja por meio da ação política concreta dos grupos sociais.

O objetivo do trabalho foi o de provocar questionamentos, apresentar uma ótica diversa sobre o tema, sem a pretensão de apresentar uma definição estática e totalizante. Por isso, considerando que os direitos humanos estão em incessante processo de construção, na dialética da humanidade, remanesce para futuras contribuições o convite à questão: o que são direitos humanos?

\section{Referências}

BALLESTRIN, Luciana. América Latina e o giro decolonial. Revista Brasileira de Ciência Política, n. 11. Brasília, maio/ agosto de 2013, 89-117, 2013.

BOBBIO, Norberto. A Era dos Direitos. Rio de Janeiro: Elsevier, 2004.

CHAUÍ, Marilena; SANTOS, Boaventura de Sousa. Direitos humanos, democracia e desenvolvimento. São Paulo: Cortez, 2013.

COMPARATO, Fábio Konder. A Afirmação Histórica dos Direitos Humanos. 11 ed. São Paulo: Saraiva, 2017. 
FLORES, Joaquin Herrera. A (re)invenção dos direitos humanos. Tradução de Carlos Roberto Diogo Garcia et at. Florianópolis: Boiteux, 2009.

FLORES, Joaquin Herrera. Direitos Humanos, Interculturalidade e Racionalidade de Resistência. Sequência, Santa Catarina, v. 23, n. 44, 9-29, 2002.

GALEANO, Eduardo. O Livro dos Abraços. Tradução de Eric Nepomuceno. 9 ed. Porto Alegre: L\&MP, 2002.

GROSFOGUEL, Ramón. Para descolonizar os estudos de economia política e os estudos pós-coloniais: transmodernidade, pensamento de fronteira e colonialidade global. In SANTOS, Boaventura de Sousa; MENESES, Maria Paula (Org.). Epistemologias do Sul. São Paulo: Cortez, 2010.

HESPANHA, Antônio Manuel. Pluralismo jurídico e direito democrático. São Paulo: Annablume, 2013.

HUNT, Lyn. A Invenção dos Direitos Humanos: uma história. Tradução de Rosaura Eichenberg. São Paulo: Companhia das Letras, 2009.

LAPLANTINE, François. Aprender Antropologia. São Paulo: Brasiliense, 2003.

LARAIA, Roque de Barros. Cultura: um conceito antropológico. 19 ed. Rio de Janeiro: Zahar, 2006.

LYRA FILHO, Roberto. O que é Direito. São Paulo: Brasiliense, 2006.

MAZUOLLI, Valerio de Oliveira. Curso de Direitos Humanos. 5 ed. Rio de Janeiro: Forense, 2018.

MIGNOLO, Walter D; WALSH, Catherine. On Decoloniality: concepts, analytics, praxis. Durham: Duke University Press, 2018.

PANIKKAR, Raimundo. Seria a noção de direitos humanos um conceito ocidental? In Direitos Humanos na Sociedade Cosmopolita. BALDI, César Augusto (org.). Rio de Janeiro: Renovar, 2004.

QUIJANO, Anibal. Colonialidade do poder e classificação social. In SANTOS, Boaventura de Sousa; MENESES, Maria Paula (Org.). Epistemologias do Sul. São Paulo: Cortez, 2010.

PÉREZ LUÑO, Antonio Enrique. Derechos humanos, Estado de derecho y Constitución. 4. ed. Madrid: Tecnos, 1991.

RAMOS, André de Carvalho. Curso de Direitos Humanos. 5 ed. São Paulo: Saraiva, 2018.

SANTOS, Boaventura de Sousa. Por uma Concepção Multicultural de Direitos Humanos. In Direitos Humanos na Sociedade Cosmopolita. BALDI, César Augusto (org.). Rio de Janeiro: Renovar, 2004. 
SANTOS, Boaventura de Sousa. Para além do Pensamento Abissal: das linhas globais a uma ecologia de saberes. In SANTOS, Boaventura de Sousa; MENESES, Maria Paula (Org.). Epistemologias do Sul. São Paulo: Cortez, 2010.

SOUSA JÚNIOR, José Geraldo. O Direito Achado na Rua: concepção e prática. Plataforma para um Direito emancipatório. In SOUSA JÚNIOR, José Geraldo (org.). O Direito Achado na Rua: concepção e prática. Rio de Janeiro: Lumen Juris, 2015.

SOUSA JÚNIOR, José Geraldo. O Direito Achado na Rua: concepção e prática. In SOUSA JÚNIOR, José Geraldo (org.). Introdução crítica ao direito. 4 ed. Brasília: Universidade de Brasília, 1993.

WALSH, Catherine. Interculturalidade Crítica e Pedagogia Decolonial: in-surgir, reexistir e re-viver. Tradução de Maria Angélica Lauriano. In CANDAU, Vera Maria (org.). Educação Intercultural na Amércia Latina: entre concepções, tensões e propostas. Rio de Janeiro: 7 letras, 2009.

WARAT, Luis Alberto. A Rua Grita, Dionísio! Direitos humanos da alteridade, surrealismo e cartografia. Rio de Janeiro: Lumen Juris, 2010.

WARAT, Luis Alberto. Surfando na Pororoca: Ofício do mediador. DAL RI JÚNIOR, Arno et al (org.). Florianópolis: Fundação Boiteux, 2004.

WEIS, Carlos. Direitos Humanos Contemporâneos. 3 ed. São Paulo: Malheiros, 2014.

WOLKMER, Antonio Carlos. Pluralismo Jurídico: fundamentos de uma nova cultura no Direito. 3 ed. São Paulo: Alfa Omega, 2001.

WOLKMER, Antonio Carlos. Pluralismo jurídico, direitos humanos e interculturalidade. Revista Sequência, n. 53, dezembro de 2006, p. 113-128.

WOLKMER, Antonio Carlos. Teoria Círica dos Direitos Humanos. In RADAELLI, Samual Manica; SIDEKUM, Antonio; WOLKMER, Antonio Carlos (orgs.) Enciclopedia Latino-Americana de Direitos Humanos. Blumenau: Edifurb/Nova Petrópolis, 2016.

Data de recebimento: 13.03 .2020

Data de aprovação: 20.07.2020 